SHORT REPORT

\title{
Pseudo-Gaucher cells in mycobacterial infection: a report of two cases
}

\author{
P Dunn, M-C Kuo, C-F Sun
}

J Clin Pathol 2005;58:1113-1114. doi: 10.1136/jcp.2004.018176

This report describes two cases of mycobacterial infection with pseudo-Gaucher cells. Both patients had no clinical evidence of inherited Gaucher disease. The first case was a patient with AIDS and Mycobacterium avium intracellulare involving the lung, spleen, and bone marrow. The bone marrow aspirates showed many histiocytes with needle-like inclusions. Acid fast staining showed that these histiocytes contained acid fast bacilli. Bone marrow biopsies revealed granulomatous lesions with aggregates of foamy histiocytes. The second case was an alcoholic patient with Mycobacterium kanasassi infection involving the lung and lymph nodes. The lymph node aspirates showed infiltration of the same cells with acid fast bacilli in the cytoplasm.

$\mathrm{T}$ he Gaucher cell is the pathological hallmark of Gaucher disease. Because of a congenital deficiency of $\beta$ glucocerebrosidase, glucocerebroside deposits in the cytoplasm of histiocytes result in foamy histiocytes. ${ }^{1}$ PseudoGaucher cells are histiocytes with cytoplasm containing needle-like inclusions, resembling Gaucher's cells. These pseudo-Gaucher cells have been demonstrated in chronic myelogenous leukaemia, thalassaemia, multiple myeloma, acute lymphoblastic leukaemia, Hodgkin disease, nonHodgkin lymphoma, and myelodysplastic syndrome..$^{2-6}$ Two reports have described pseudo-Gaucher cells in tuberculosis. One was in a patient with AIDS and Mycobacterium avium intracellulare infection and another was in a patient with pulmonary tuberculosis. ${ }^{78}$ Here, we present two cases of mycobacterial infection with pseudo-Gaucher cells in lymph nodes and bone marrow, respectively.

"Pseudo-Gaucher cells are histiocytes with cytoplasm containing needle-like inclusions, resembling Gaucher's cells"

\section{CASE REPORTS \\ Case 1}

A 28 year old man visited our outpatient department because of general malaise and body weight loss of about $2 \mathrm{~kg}$ in November 2003. Upon physical examination, he was diagnosed with mild anaemia but no lymphadenopathy or hepatosplenomegaly. Initial investigations showed: haemoglobin, $8.4 \mathrm{~g} /$ litre; white blood cell count, $5.9 \times 10^{9}$ /litre; platelets, $181 \times 10^{9}$ /litre; and albumin, $2.8 \mathrm{~g} /$ litre. Six weeks later, he was admitted because of a cough and progressive shortness of breath for one month. On physical examination, he was found to be extremely pale and splenomegaly was detected (10 cm below the lower costal margin). A haemogram showed: haemoglobin, 3.9 g/litre; white blood cell count, $4.8 \times 10^{9}$ /litre $(93 \%$ neutrophils and $3.5 \%$ lympho-

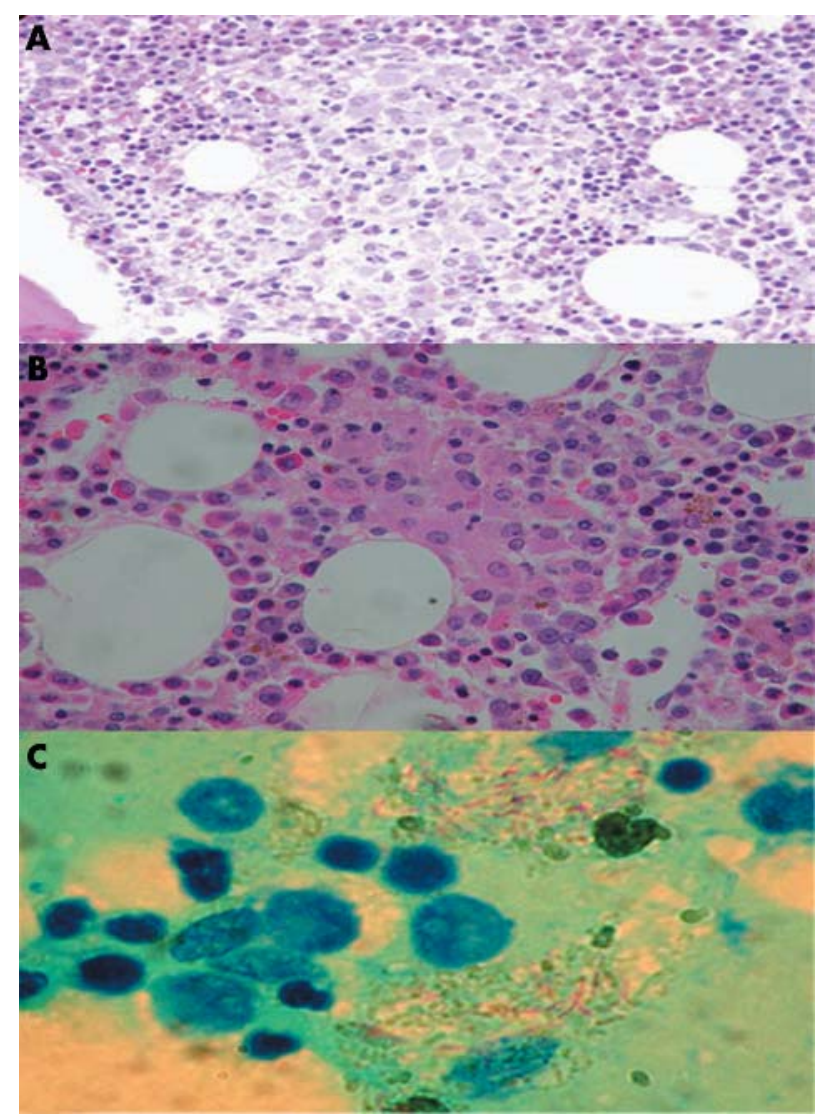

Figure 1 (A) Bone marrow aspirates showing many histiocytes with needle-like inclusions in the cytoplasm in patient 1. (B) Bone marrow biopsy showing granulomatous lesions with aggregates of histiocytes in patient 1. (C) Lymph node aspirate showing acid fast bacilli in foamy histiocytes in patient 2.

cytes); and platelets, $2.4 \times 10^{9}$ /itre. Bone marrow aspirates showed many histiocytes containing crystal-like inclusions (fig lA) or cell debris. These histiocytes were about $20 \mu \mathrm{m}$ in diameter, and had an eccentric nucleus and pale blue cytoplasm. Acid fast bacilli (AFB) staining of bone marrow aspirates demonstrated the presence of these organisms in these histiocytes, whereas periodic acid Schiff staining was negative. Bone marrow biopsies revealed aggregates of histiocytes that looked like granulomas (fig 1B). Antibody to human immunodeficiency virus (HIV) was positive. A chest $x$ ray showed peribronchial infiltration on the bilateral lower lung field. AFB stain of sputum was positive. Culture of sputum grew Mycobacterium avium intracellulare. The patient

Abbreviations: AFB, acid fast bacilli; HIV, human immunodeficiency virus 
responded well to antituberculosis and antiretroviral regimens.

\section{Case 2}

This 61 year old man is an alcoholic. He suffered from cough and afternoon fever in May 2002. Chest $x$ rays showed tuberculosis lesions over the right upper lobe with pleural effusion. Sputum culture grew Mycobacterium kanasassi. He was treated with antituberculosis drugs. Two months after starting treatment, his cough and fever subsided. Five months later, he was admitted because of jaundice for two weeks. Laboratory studies showed a total bilirubin of $238 \mathrm{mg} /$ litre. An anti-HIV test was negative. Chest $x$ rays revealed consolidation over the bilateral lung. Multiple lymphadenopathy over the bilateral neck, supraclavicular, and inguinal areas was noted. A cervical lymph node aspirate showed infiltration of Gaucher-like cells. AFB stains of lymph nodes (cervical, axillary, and inguinal lymph nodes) revealed acid fast bacilli in these histiocytes (fig $\mathrm{lC}$ ). Cultures of sputum and lymph node aspirates grew $M$ kanasassi. Bone marrow biopsy showed no granulomas or abnormal histiocytes, and bone marrow culture for mycobacterium disclosed no growth. The patient died of disseminated mycobacterial infection one month later.

\section{DISCUSSION}

Typical Gaucher cells have a characteristic "wrinkled tissue paper" appearance of the cytoplasm as a result of deposition of glucocerebroside. These cells can be up to $60 \mu \mathrm{m}$ in diameter. Some cells have tubular or fibrillary structures in the cytoplasm. ${ }^{1}$ In the presence of cytopenia related symptoms, hepatosplenomegaly, and typical Gaucher cells in the bone marrow, the diagnosis of Gaucher disease is not difficult. Both patients were normal before the presentation of tuberculosis, and in case 2 there were no abnormal histiocytes in the bone marrow.

Pseudo-Gaucher cells in chronic myelogenous leukaemia resulted from rapid cell turnover with glucocerebroside deposition in the cells. The colour of the cytoplasm in pseudo-Gaucher cells of chronic myelogenous leukaemia is bluer than that in classic Gaucher cells. Pseudo-Gaucher cells in thalassaemia or other haematological malignancies are extremely rare, and are usually presented as case reports.

\section{"Pseudo-Gaucher cells might be the morphological hall-} mark of mycobacterial infection in immunodeficiency"

Solis et al reported the first case of pseudo-Gaucher cells in $M$ avium intracellulare infection in an HIV infected patient. ${ }^{7}$ They noted massive infiltration of the lamina propria of the bronchial mucosa, lung parenchyma, and bone marrow with foamy histiocytes. There were numerous needle-like structures in the cytoplasm of the histiocytes. These foamy histiocytes were rounded, 25-30 $\mu \mathrm{m}$ in diameter, and had abundant pale blue cytoplasm and a peripherally displaced nucleus. They noted that granulomas are poorly formed with no lymphoplasmacytic reaction. Later, Links et al reported another case of tuberculosis with pseudo-Gaucher cells. This patient had pulmonary tuberculosis (sputum culture grew $M$ tuberculosis) with fatal respiratory failure, and the HIV status was unknown. ${ }^{8}$ At necropsy, pleural culture revealed $M$ tuberculosis. Large foamy histiocytes with numerous needlelike structures infiltrated the liver, bone marrow, lymph nodes, spleen, and lungs. Special stains for AFB and fungi and periodic acid Schiff staining of these organs were
Take home messages

- We describe two immunocompromised hosts (one with AIDS and the other an alcoholic) with mycobacterial infection

- Pseudo-Gaucher cells were found in the bone marrow and lymph nodes of these patients, respectively

- These pseudo-Gaucher cells contained needle-like inclusions and acid fast bacilli

- A diagnosis of mycobacterial infection in immunodeficiency should be suspected in the presence of psuedoGaucher cells

negative. Both patients died shortly after diagnosis. In our studies, pseudo-Gaucher cells were smaller than typical Gaucher cells. Periodic acid Schiff staining of these cells was negative in contrast to a strongly positive reaction in typical Gaucher cells. There was no "wrinkled paper appearance" in the cytoplasm-the characteristic findings of Gaucher cells. Thus, it is not difficult to differentiate these cells from classic Gaucher cells by microscopy. In our patients, only histiocytes infected by AFB had a Gaucherlike cell appearance. Therefore, pseudo-Gaucher cells may result from inadequate digestion of mycobacterial bacilli by histiocytes. Both patients were in an immunodeficient state, with poor function of histiocytes.

In conclusion, pseudo-Gaucher cells might be the morphological hallmark of mycobacterial infection in immunodeficiency. In the presence of pseudo-Gaucher cells, AFB stains should be performed immediately and antituberculosis regimens should be prescribed if the result is positive. However, the presence of pseudo-Gaucher cells might predict a very poor outcome.

\section{Authors' affiliations}

P Dunn, M-C Kuo, Division of Haematology-Oncology, Department of Internal Medicine, Chang Gung Memorial Hospital, 199 Tung Hwa North Road, Taipei 105, Taiwan

C-F Sun, Department of Pathology, Chang Gung Memorial Hospital P Dunn, School of Medicine, Chang Gung University

Correspondence to: Dr P Dunn, Division of Haematology-Oncology, Department of Internal Medicine, Chang Gung Memorial Hospital, 199 Tung Hwa North Road, Taipei 105, Taiwan; dunnpo@adm.cgmh.org.tw

Accepted for publication 4 November 2004

\section{REFERENCES}

1 Beutler E. Gaucheri's disease. N Engl J Med 1991;325:1354-60.

2 Zidar BL, Hartsock RJ, Lee RE, et al. Pseudo-Gaucher cells in the bone marrow of a patient with Hodgkin's disease. Am J Clin Pathol 1987:87:533-6.

3 Zaino EC, Rossi MB, Pham TD, et al. Gaucher's cells in thalassemia. Blood 1971;38:457-62.

4 Scullin DC, Shelburne JD, Cohen HJ. Pseudo-Gaucher cells in multiple myeloma. Am J Med 1979;67:347-52.

5 Carrington PA, Stevens RF, Lendon M. Pseudo-Gaucher cells. J Clin Pathol 1992; $45: 360$

6 Stewart AJ, Jones RD. Pseudo-Gaucher cells in myelodysplasia. J Clin Pathol 1999:52:917-18.

7 Solis OG, Belmonte AH, Ramaswamy G, et al. Pseudogaucher cells in Mycobacterium avium intracellulare infection in acquired immune deficiency syndrome (AIDS). Am J Clin Pathol 1986;85:233-5.

8 Links TP, Karrenbeld A, Steensma JT, et al. Fatal respiratory failure caused by pulmonary infiltration by pseudo-Gaucher cells. Chest 1992;101:265-6. 